\title{
Building Learning System for Content Knowledge and Social Knowledge
}

\author{
https://doi.org/10.3991/ijet.v13i01.6912 \\ S.M.F.D Syed Mustapha \\ Taif University, Taif, Saudi Arabia \\ smfdsm@gmail.com; syed.malek@tu.edu.sa
}

\begin{abstract}
In the late 50's or early 60's, there were huge interests towards building learning systems for individual learning and they are called with various names such as Intelligent Tutoring System, Microworld, Computer Based Training, Computer Aided System, Intelligent Computer Aided Instruction and others. They are made to be different with regard to the technological approaches and the learning pedagogies, knowledge models and student models. Over the years, the interest of building learning systems has migrated from individual learning on content knowledge to community learning as the result of the recent Web 2.0 and Web 3.0 sociotechnological wave. The paper describes the work that was done to develop the learning system in both situations - content knowledge and social knowledge where the experiences mainly in capturing the knowledge and representing them are different. The paper signifies the differences in terms of developing experiences and methodologies for building the content knowledge and social knowledge based on the previous works. The finding of the previous works tells that context knowledge is derived from structured sources and also referred to single-sourced expertise while the social knowledge is more challenging due to its unknown structure of knowledge as well as may derive from various experts.
\end{abstract}

Keywords-Intelligent Tutoring System, Social Knowledge, Content Knowledge, Community Learning

\section{Introduction}

Literature has shown the interest in building learning systems existed earlier than late 40 s or early 50 s among the researchers in the field of artificial intelligence and cognitive sciences. Among the major concerns that were raised to trigger the interest lie within the fundamental research questions - how learners learn, how knowledge is encoded with the capability to reason, how pedagogy can be instituted in the learning system and how an individual learning can be supported using computer technology. Throughout these years, there is an evolutionary of the technological growth that allow researchers to explore further in building learning system to support learning at individual level to community at large. Hence, the approaches in knowledge capturing and modelling, knowledge dissemination and pedagogical approaches will be greatly 
diversified. This paper describes the approaches in building learning system for individual learning and community through knowledge building collaboration and the comparison of the approaches. The difference made is that the knowledge type for individual learning system is called "content knowledge" while for community learning system is called "social knowledge". Understanding the types of knowledge is concomitant to building the right learning system as well as modelling it. There is phenomenal change in building learning system for content knowledge based on an individual expert's experiences to social knowledge which is primarily constructed from community collaborative effort and behavior development. Consequently, this introduces the technological paradigm on the system development methodology and underpinning infrastructure which will be explored more in the following discussions.

\subsection{History and evolution}

Building learning system has its own history conceptualizing the technological development that coexists to support the delivery of the knowledge content and learning activities. For that reason, they were born with numerous names and infinite in numbers (e.g. CAI, ICAI, CBT, CAL, CALL, CEI, CBI, CSCL, E-Learning, E-Learning 2.0, ICAL, IBL, ILE, ITS, M-Learning etc.), perhaps reflecting the technology or teaching delivery approach. We lay down some historical notes to some of these selected systems, signifying the technological difference and evolvement of its teaching and learning.

The revolutionary theory in educational psychology on individual learning or student-centered learning was germinated as early as in 1920s when the first teaching machine was invented by Sydney L. Pressy. However, in 1950s there were two prominent ones; first by the Harvard University Psychology Professor, Dr B.F. Skinner (Skinner, 1961). He purported that each student demonstrates idiosyncrasy in learning and requires different treatment on critical topics. He invented "Teaching Machine" based on linearity which was named as Skinnerian-type machine where learning could take place in individual setting rather than in a classroom environment. The machine is programmed with hundreds of frames where each represented morsels of topics and information to be drilled with the student. There were other contemporary efforts on the teaching machine that were discussed in the literature (Galanter, 1959; Lumsdaine and Robert, 1960). Blyth (1960) experimented using his machine as the tool for teaching students that resulted in reducing the time of teaching while improving the learning capacity of the student.

Even though Skinner advocated on individual learning, Skinnerian machine at that present technology can only support "linear program". The learning sequence is rather fixed into the system as one-way path towards completing the entire lessons. The second type of teaching machine was invented by Crowder (1959), who introduced "branching programs" technique as the alternative approach to Skinner's program. It used frames but allows repetition to the frames throughout developing the learning path and completing the entire syllabus. Skinner's program encouraged learner's individual response to problem through "fill-in the blanks" concept and auxiliary support (e.g. hints, prompts or suggestion). On the other hand, Crowder's teaching 
machine posed multiple-choice answer, allowed "feedback" when learner gave the incorrect ones before repeating the topics and assessment and proceeded to the next level upon success.

Reflexive Model Era: The technology adopted in the teaching machine did not allow generation of new materials, required pre-stored instruction, responded based on "correct" or "incorrect" input, had limited learning pathway (i.e. no opportunity for self-exploration by the student) and knowledge content that was delivered was not tailored to the individual leaner.

In the late $60 \mathrm{~s}$ and early $70 \mathrm{~s}$, new generation of teaching machine that was known as "generative system" or "adaptive system" was built that was capable to generate new sets of problems and to provide solutions. Computer-Assisted Instruction (CAI) was among the early systems that were built with basic capability to display problems to students and accumulate the scores which is based on the response given by the student (Uhr, 1969). Uhr's system made appropriate selection of the problems based on the performance of the students while performing on his system. There were other similar works on CAI systems with similar features and capabilities (Suppes, 1967; Woods and Hartley, 1971).

Generative System Era: The CAI individualized the presentation of teaching materials which was based on the learner's performance. In other words, each learner would have experienced different learning path in comparison to using Reflexive Model. Another progression was the auto-generated problems and solutions that enriched the learning space. One of the strength of the CAI in this era was that learner's performance was measured as the basis to gauge the student's level of competence in the subject.

Despite the enhancement of CAI in comparison to the technology developed in the Reflexive Model Era, scientists in the 80s had made another major technological melioration on the CAI capabilities which are the followings:

1. Expert knowledge model - CAI does not possess well-defined knowledge of the subject matter such that without this, it will never be able to mimic the actual performance of the human tutor. The knowledge has to be modelled in a way that can be articulated clearly.

2. Student model - CAI measured the student's performance but it had no means to determine the gap between student's levels of understanding to the expert's. The gap fillers differ for each individual student and hence it requires customized approach, so-called "personalized delivery".

3. Pedagogical model - CAI had very limited teaching strategy as it was not able to analyze the error made by the student that could be used for diagnosis and proper selection of teaching strategy.

4. User interface - the available technology during the development of CAI was still primitive and limited to be able to process complex communication language and symbols. 


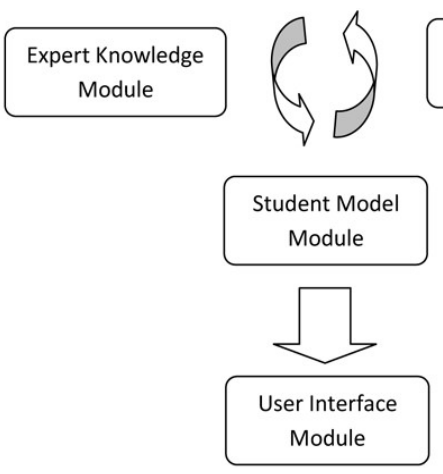

Fig. 1. Intelligent Tutoring System General Architecture

ICAI/ITS - the four major criticisms stated above has set a major hallmark to the technological development of learning system. Artificial Intelligence was introduced to CAI to form new era of Intelligent Computer Aided Learning or now widely known as the Intelligent Tutoring System. Its architecture was defined by various prominent researchers, albeit they may differ from each other, the common ITS components have been agreed to have Expert Model, Pedagogical Model, Student Model and user Interface Model as shown in Figure 1.

It is very interesting to note that since the origination of ITS, research for each of these areas is still an ongoing and new problems have sparked for further exploration until today. The reasons are that the fast growing of the following areas has made building Expert Model, Pedagogical Model, Student Model and User Interface Model to be the unresolved problems:

1. Knowledge media and representation the knowledge media has been greatly influenced by the continuous development of multimedia software tools and objects as well as the hardware devices. Researchers in the field of artificial intelligence started with production rules, semantic network and first order logic and further developed frame-based knowledge representation, case-based reasoning, qualitative models and semantic web technologies.

2. Communication and information delivery technologies the communication technologies have changed situated learning like in the class room to mobile learning.

3. Teaching and learning strategies the traditional "sage on stage" has migrated into student-centered learning mode e.g. problem-based learning. The "drill-andpractice" method that is applied to all should be customized for individualized needs of the learners.

4. Knowledge type and learning culture and communities from the early days, knowledge that is stored in the teaching machine or in the intelligent tutoring system is categorized as "content knowledge" which is structured and formal. Today, social computing and the growing interests in social media introduce "social knowledge" which is unstructured and informal. That also changes the culture of learning from modelling knowledge of a single expert to multiple experts. 
The above developments will continue to pose new research challenges since the interest in building learning system is not only for learners in the formal educational institution but also industrial workers and professionals that require in-house training. Computer-Based Training (CBT), Flight Simulators, Computer Aided Simulator are the training tools that have been built successfully.

The followings are two examples in developing learning systems respectively for content knowledge and socially-built knowledge which were done in the past; Firstly, using the content knowledge for modeling an expert knowledge for an individual learning and; Secondly, using social knowledge for the community learning. The work done in modelling the rheologist's knowledge for the content knowledge and modelling community of practice as an illustration of for modelling social knowledge.

\section{Modeling Rheologist's Knowledge}

Rheology is a study of deformation and flow of a matter, that is to investigate the behavior of the matter when stress and strain are applied. Rheologists are the expert who may come from various backgrounds, such as chemical engineering, material sciences, food processing engineering, applied mathematics and instrument design engineering. The rheometers that are designed by engineers are devices in the laboratory that are used to measure the materials ${ }^{1}$ that are categorized to possess more than one property besides viscosity, which could be the non-Newtonian fluid or viscoelastic solid. The field of rheology remains to be complex and only taught as an advanced course such that knowledge in this field can be acquired from the experts who have long years of experiences. This is the primary factor that motivated the work in building learning system to assist practitioners in understanding and applying the concept as well perform data analysis. A good introductory reference for rheology can be referred to Barnes et al (1989).

\subsection{Rheological Process}

Rheological software is used by rheological experts together with rheometer while performing data analysis. The software is designed and developed by the experts with sophisticated functions and tools for effective use in getting accurate results. The software serves well for experienced experts but likely fallible for the ordinary lab operators and practitioners. What's the different? The software requires one to have an understanding on rheological models, rheometer usages and procedures on data analysis. There are two processes - symbolic computation which involves rheometer experimental preparation, visual observation and interpretation on the rheogram, identifying specific properties on different parts of the rheogram; and non-symbolic computation which is model-fitting and model-selection. There is compendium of rheological models to choose from which experts are able to determine based on their ex-

\footnotetext{
${ }^{1}$ Materials in this manuscript are referred to substance obeying the characteristics of both NonNewtonian fluid and Viscoelastic solid.
} 


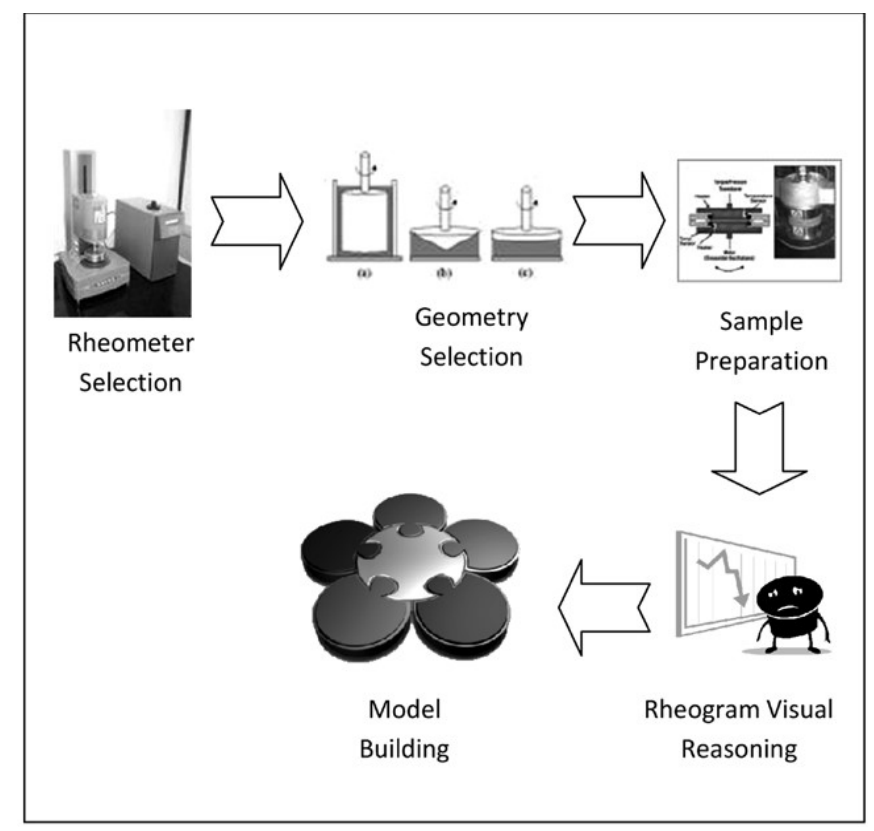

Fig. 2. Symbolic Computation Process for Rheologist

periences. The entire process that involves the above two processes are as shown in Figure 2.

The selection of rheometers requires one to possess vast knowledge and deep understanding of the material behavior that needs to be simulated in the real world problem. Rheometer is also used to capture specific properties of the material such as the strain, stress, relaxation mode, on a given rheometrical configuration such as frequency, temperature and time. There are two types of rheometer that are used to measure the fundamental rheological properties which are rotational and tube-type (Steffe, 1996). The rotational can be driven by a constant angular velocity or dynamic mode. The controlled stress is used for creep data analysis, low shear rates and yield stress investigation. The controlled rate is suitable for process engineering problems. The expert chooses the right rheometer based on what kind internal structure of the material under investigation. Each rheometer has different set of geometries to choose from, based on the material and the type of the rheometer where each has its own geometry. For example, for rotational rheometer uses parallel plate, cone and plate and concentric cylinder while tube type uses pipe, glass capillary and high pressure capillary. The understanding on rheometer usages is not formally available and commonly experts are referred. Sample preparation is another procedure that has never been standardized or understood except by the rheologists (Amin and Carrington, 2009). Another process performed by the expert is reasoning with the graph, so-called rheogram. Rheogram is produced from the captured data generated by the rheometer. In ideal situation, the behavior of the materials can be interpreted through visual observation on the rheograms; nevertheless, rheograms could also display abnormalities 
due to erroneous on sample preparation, misalignment of geometry etc. The final stage is model building where the expert has to determine the composition of the rheological models that best describe the rheological data.

In non-symbolic computation as shown in Figure 3, rheologist deals with range of rheological models to find the best-fit for the entire rheological data set. In order to achieve highest accuracy on the model fitting, all of the available models have to be tested. The challenge is to minimize the number of rheological models used to fit the entire rheogram at the same time. Somehow, the experts who have long experience with this will be able to quickly spot the right model for different parts of the curve.

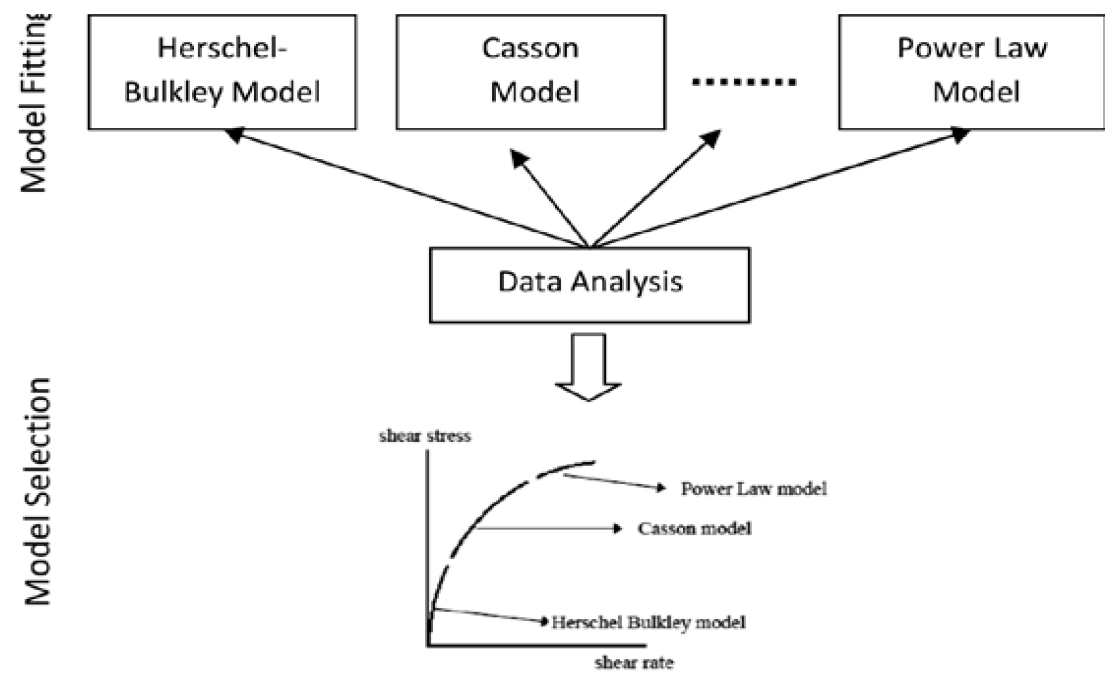

Fig. 3. Non-symbolic Computation Data Analysis (Model selection - adapted from (Syed Mustapha et al (1999))

\subsection{Modeling Knowledge}

Modelling expert's knowledge requires a systematic approach in knowledge engineering (Kendal and Creen, 2007). The general procedures in knowledge engineering involve the following steps:

1. To recognize the types of knowledge that is used by the expert - declarative knowledge, structural knowledge, procedural knowledge, heuristic knowledge and meta-knowledge.

2. To identify the methods and approaches that is commonly adopted by many experts and also those that are unique to certain experts.

3. To identify the suitable knowledge representation techniques that fits the purpose of the knowledge use.

To elicit and elucidate the expert knowledge and translate into codified form that is executable on any programming language. 


\subsection{Automated Rheology Model Builder}

The purpose of the model builder is to provide close-guided advisory to the lab operators in performing complex data analysis. Unlike in the traditional data analysis, the selection of the models is guided by the qualitative analysis on the graph (using qualitative interpretation). For example, for a simple linear line graph where viscosity parameter is constant, on the shear-stress and shear-rate plot, will easily eliminate other non-Newtonian models that are irrelevant.

Mixed-initiative approach is adopted as the learning and teaching strategy for the Rheometer Advisory System (Syed Mustapha \& Phillips, 2002). Learner could perform the full data modelling with or without the intervention of the system or could choose to allow mixed initiative between the system and the learner. Since, accuracy of the results is sensitive to the choice of the models, the system provides a recommendation and prompts a dialogue box to warn any discrepancy on the findings between the manual and automated initiative (Syed Mustapha, et.al, 1999, pp 267).

\subsection{Rheometer Advisory System (RAS) in the Perspective of ITS}

The core intelligence of RAS is built on the automated graph analysis based on qualitative model reasoning. With this capability, the system is able to recognize abnormalities in the graph that is generated from the error in the conducting the experimental procedure. In RAS, expert knowledge is modelled as the knowledge task in performing the data analysis. The knowledge task can be presented in various task models as described by Mori et al (2002). Marshak (1997) and Trætteberg (1999) describes four dimensions that model the task, namely, action structure, actors, tools and information (sources). The actions comprise of task and subtask which are the series of segment modelling of the rheogram. The pre-condition is the minimum size of the segment length that has to be sufficient for modelling and the post-condition set the minimum correlation before accepting any of the non-Newtonian models. The action includes the interception of the explanation dialogue box to alert the learner of possible misconception when performing certain action. The actor in this case conceptualizes the artefact which is the advisory component that monitors and guides the user throughout the learning process. Unlike the standard application of the actor concept where users are modelled to the task based on the level of expertise and knowledge, the learning system feigns that all users are beginners. Nevertheless, the advanced users will receive less interceptions and support by the system in comparison to the beginner.

The actions include the selection of geometries, choosing the rheometers, rheological model fitting, rheogram visual analysis and others. Objects can be materials or abstractions that are used to support the task operation. The rheogram is the core object for the segmentation task while the rheological models are the main object source for reference. The data generated from the rheometer is the object for fluid behavior characterization which is projected to learners as preludes to rheological modelling. The entire session on rheological modelling involves several tools, the geometries, the rheometers, rheological data and models and rheometer advisory system. 


\subsection{Concluding remark on Content Knowledge}

Rheometer Advisory System (RAS) was built based on the consensual knowledge that is derived from established sources mainly from the expert in the field. RAS mimics the human's capability in the visual reasoning over the rheogram to perform the graph analysis. The analysis adopts qualitative approach that is a simplification method that eliminates the unnecessary massive quantitative computation. The graph is interpreted based on the expert's knowledge on several types of rheological behavior. Subsequently, the appropriate model is chosen to represent the graph segments. The entire process is captured into the four-dimensional tasks model. RAS is a computer-based training system for industrial laboratory where the fundamental knowledge is built based on the formal theory and practical experiences of a rheological expert.

In conclusion, RAS is an example of building intelligent tutoring system based on content knowledge. The source of knowledge is usually based on single expert's view or established references such that in building ITS based on content knowledge requires a huge financial investment and massive development effort even to build a huge system for a small functionality. Learning from the knowledge-based system (CYC) project, it has been more than 15 years with millions of dollars invested in the project. The Web 2.0 and Web 3.0 have introduced social knowledge building with some web-based applications such as Wikipedia and other folksonomy approaches that emphasize on community as the resources to knowledge building ( $\mathrm{Wu}$ et al, 2006).

\section{Content Knowledge to Social Knowledge}

Modelling social knowledge brings about new approaches to the conceptualization of learning, knowledge reposition, knowledge artefacts, learning objects, learning process and knowledge building. The term "social knowledge" has been debated in different contexts and definitions. However, the kernel to all is that social knowledge lies in the context of the community.

Prior to the discussion on the issues and challenges in modelling social knowledge, understanding the significances of social knowledge to the learning theory practiced in organization and learning institution (e.g. universities, colleges or training centers) is necessary.

\subsection{What is the Learning Theory now?}

There is an old saying "it is not what you know, but who you know" and if this is true, somewhat this can affect the fundamentals of the way we learn and what to be learned. Personally, I believe this is true in the real working life. A fresh graduate who commences his first day work as engineer may find a great deal of challenge to find out the trustworthy contractors and suppliers and the ones with the best service quality without first refer to his colleagues. His deep understanding on content knowledge about circuit theory and thermodynamics contribute less in achieving the 
working goal. Let us ask the programmers, who do they turn to when their programming codes are in difficulties - the textbooks and manuals? More often than not, technical forums will be the preferred points as they provide solutions and expression out from their own experiences which are not covered in the formal references.

Model learning theories emphasizes on the "interactional with community members" as the main source of learning. Hoadley (2005) stated the modern learning theory constitutes the four classical theories, namely, behaviorist learning, developmental learning, cognitive learning and sociocultural learning. The behaviorist learning suggests the principle of stimulus-response where learner begins with passive behavior that is subjected to change, environment that will shape the change and reinforcement to ensure the likelihood of learning to take place. Developmental learning describes the learning through interaction with the external objects and develops understanding to maturity state. Cognitive learning exhibits the learning of a learner through a new regeneration of mental conception and representation. Sociocultural learning associates the social behavior and practices of the community within the development process of learning.

Social knowledge is spawned from the community activities that underlay by the four learning models. New comers to the learning community rebuild their characteristics through several processes of adaptation and renewing of social identity against the existing community culture and practices (behaviorism). Learning resources and artefacts are germinated as the product of the learning actions and participation that the community members undertake (developmental). Knowledge is shared and its meaning is negotiated that possibly new knowledge is regenerated by the members in the community (cognitive learning). Members of the community engage in a mutual agreement towards a shared goal and objective. They craft unique community distinctions and belongings that separate them from other communities in terms of values, cliché, slang, jokes and insights (sociocultural).

\subsection{Learning in Community of Practice}

Community of Practice (CoP) is the recent social learning theory that has been widely adopted by organizations. It has been introduced since the realization of its existence. In this sense, the presence of $\mathrm{CoP}$ has existed even before the theory was established. It is redefined with ten important elements (Wenger, 1998) such as community structure, learning through participation and reification, negotiation of meaning, learning as temporal, boundary objects, boundary encounters, mutual engagement, joint enterprise, shared repertoire, identity.

Studio type of learning where learning is open among students. Students can observe from each other on the practices, thinking process, mistakes and corrections. Visitors can walk in to criticize the work while others can learn in peripheral manner and nuances of the comments. The justifications and reasoning that the subjected students provide will add as part of new learning experiences. Two important points to make - student as the main object of learning and references through intensive socialization from each other rather than merely with the lecturer and students are responsible to establish their own path of learning towards achieving their goal. 
Another interesting differentiation to make is between "learning about" and "learning to be" in which the former is about learning the content and the latter is about being able to do something. The immediate recall on this differentiation is the earlier separation between "content knowledge" and "social knowledge". The content knowledge is what the students need to learn about and the social knowledge helps the student to learn to be. Most of the printed and published materials contain the explicit knowledge and information which students are made compulsory to know and are examined in the assessment. Content knowledge constitutes the small part of the entire learning outcomes of the students. The social knowledge cannot be taught in explicit manner but can be the major part of the learning outcomes.

\subsection{Building Social Knowledge through Intelligent Conversational Channel}

The social-knowledge (or socially-derivable knowledge) is not formal and very much localized to certain community and culture. The lifespan of the knowledge is determined by the community acceptance at a specific juncture. Therefore, it can be easily affected by the management change, policy and regulatory, social pattern, economic situation and the people. Localization here is not referring to the group of people of the same local problem and not necessarily near geographically. In one scenario, Denning (2001, Appendix 5, pp 214) describes how the problem in Pakistan's highway was solved at instant after contacts with colleagues who had experience solving the similar problems in Jordan. Social knowledge does not reside in a wellstructured knowledge format and it is very unlikely any standard body will be able to define a standard model for its acquisition, presentation and maintenance. Social knowledge resides and distributed in all social media (e.g. blogs, forums, facebook or twitter) and other communication software such as emails, forums, e-bulletin etc. The generation of knowledge sparks at any point of acquaintance between two or more people. The great challenge is that the majority of the occurrences can be incidental and do not take place on computational platform. Due to the differences between content knowledge and social knowledge, the development tool in facilitating the learning is also different. The content knowledge which represents facts and fundamental theories can be learned and shared using courseware or computer-based learning software; while experience can be obtained from the expert system or intelligent tutoring system. Nevertheless, social knowledge requires community as the integral part of knowledge source. The process of building the system that support learning for social knowledge requires consideration given to the following factors (Syed Mustapha, 2004a; 2004b):

1. Multiplicity in learning objects - knowledge in the real world is delivered or obtained in different forms. The objects, which are used as part of the learning whether directly or indirectly is called learning object as described by Community of Practice. Radio, television or LCD screen used for advertising are examples of broadcasting system that contribute to one's knowledge. Newspaper, magazines, leaflets or brochures are pieces of information, which transform into one's knowledge when he/she reads them. Other forms of learning objects are the work- 
ing colleagues, animated or unanimated artifacts such as the copier machine, pets at home, video movies and neighbors whom one socializes with. In this respect, the expert knowledge does not come from a single source and subsequently this requires the multiplicity in methodology for delivering the knowledge. Expert's talk in the open seminars or television will be the sources for learning objects.

2. Open-world assumptions - assumption is needed when one designs a system to be used as problem-solver. The assumptions are perspective that draws the boundary of the intended world in order for the system to work successfully within the specified limit. In modelling the content-knowledge, close-world assumption is always used. Unlike the content knowledge, social knowledge does not specify the assumption as the knowledge is not modelled but shared in its original form. The knowledge contains the description about the real world problems and solution rather than the hypothesized.

3. Rapid knowledge-building - content knowledge requires a system builder to analyze and study, to model the solution, to build the system and test its performance. These processes are rather time-consuming and costly. On the other hand, the social knowledge is built by the community in a progress manner and can be learned immediately without the need of highly mechanistic and sophisticated process (Stahl, 2000; Syed Mustapha,2004c). Knowledge is presented in a human-readable format rather than machine-readable format.

4. Unorganized, ubiquitous but retrievable - content knowledge built in an expert system is structurally organized and frequently validated by the truth maintenance technology. The purpose is to avoid conflict of facts and retain consistencies in delivering solution. The retrieval of the solution depends on the reasoning technique employed in the system. Social knowledge is rather unstructured and ubiquitous. The knowledge allows conflict solutions to a single problem as it can be treated as having choices of different perspectives. Learners are not confined to solution of a single expert in this case as knowledge is contributed by several experts or nonexperts who are involved in the knowledge construction process. The social knowledge is retrieved through social interactions and dialogues with the communities.

\subsection{Unstructured Knowledge Modeling}

Prior to demonstrating the system prototype for building social knowledge, a generic diagram describing the architecture of the system that support the operation of social knowledge building as shown in Figure 4. Social knowledge is initiated by several individuals who participated concurrently in knowledge building. In an open environment, the posted knowledge is easily vetted in various ways such comments from other members or using more structured means using iconic response (like, dislike etc). The posted knowledge is observed by individuals and further decided whether to adopt for implementation. His or her personal experiences will confirm the validity of the other member's opinion who posted his/her opinion. The knowledge will become commonly acceptable if it receives various confirmation from many individuals who adopt and implement for personal experiences. The knowledge shall 


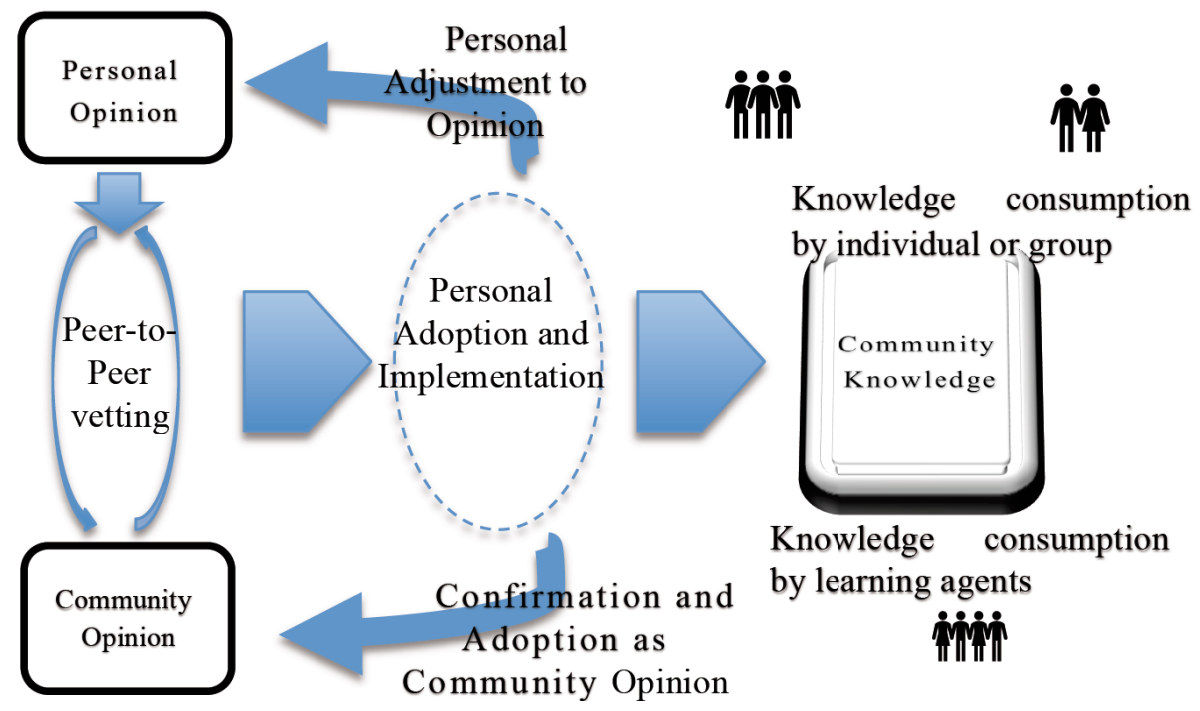

Fig. 4.

become the community knowledge when it is used and referred as non-disputable knowledge.

The following section describes the Intelligent Conversational Channel as the tools for social knowledge building.

\subsection{Components of Intelligent Conversational Channel (ICC)}

The technology of ICC is built to enable the operation of the upper stream of the knowledge management which is at the user or community level. That involves massive community interactions through text-based dialogues, sharing of learning objects in the form of standard multimedia formats, analyzing intellectual discourse based on structured argument-labelers, promoting communities through virtual presence and agent-based communities as shown in Figure 5. The four main components in ICC are the Community Channel, Hypermedia Learning Space, Discourse Communicator and Virtual Community. ICC is built to support the operations of the CoP. In ICC, the distinctive groups of CoP members are separated different community channel (for this specific example, only Community Channel $\mathrm{A}$ is shown). The formation of the community for each channel is natural selected based on the interest of the members as commonly found in the open internet forums or blogs. However, for institutional purpose, the membership can be controlled by an administrator. The example shows company's annual report is the targeted learning object which is read by member A, B and $\mathrm{C}$. Each of them posted textual messages under several categories such as opinion, argument and suggestion.

The huge accumulation of the community posted message forms the community knowledge or organizational knowledge which can potentially be analyzed. The categorized labels enhance the accuracy in identifying the community's preferences, sup- 
ports or dislikes on certain ideology and ideas. Subsequently, these are consumed by the virtual community which comprises of individual simulated agents. The collection of agents, so called virtual community, mimics the conversation of the actual members to simulate the discussion in an interactive environment (Syed Mustapha, 2004d). The reasons for having agents are to ensure community presence at all times, immediate response to queries made by the users when the actual members are absent and to incorporate embodied conversational agent (ECA) capability in future. In short, the virtual community, in addition to the real community members, builds the community structure for CoP.

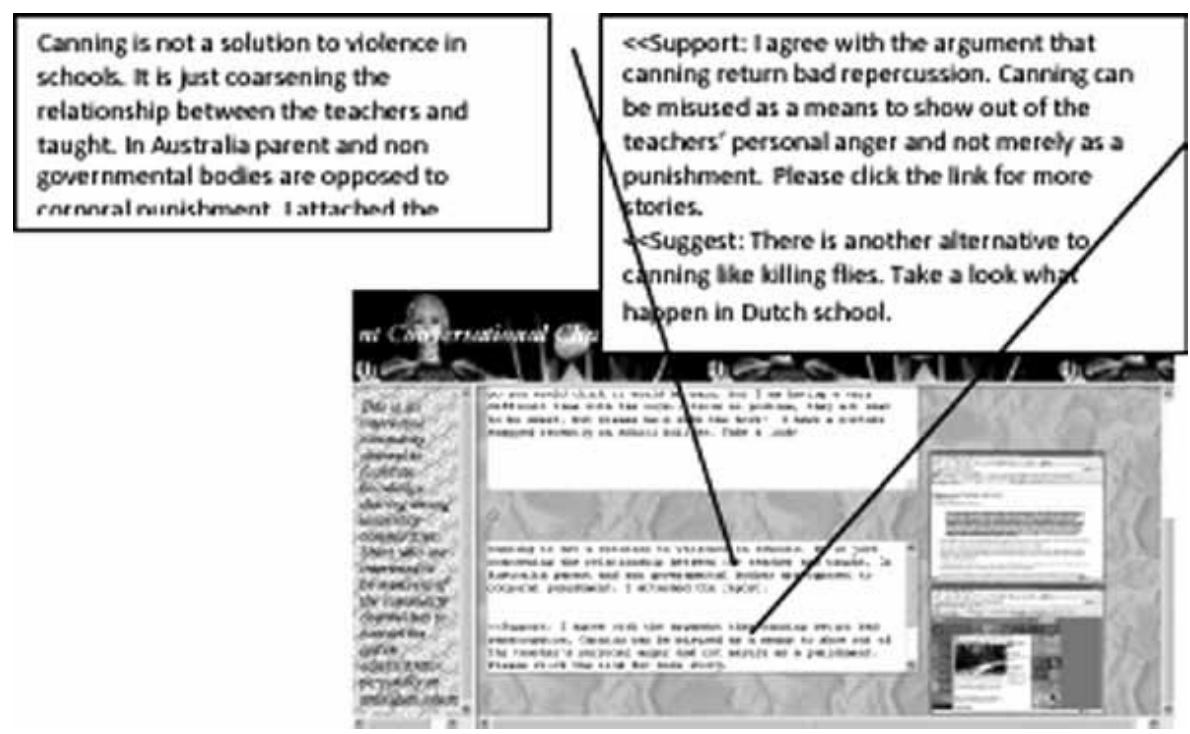

Fig. 5. Components of Intelligent Conversational Channel (adapted from (Syed Mustapha, 2004a))

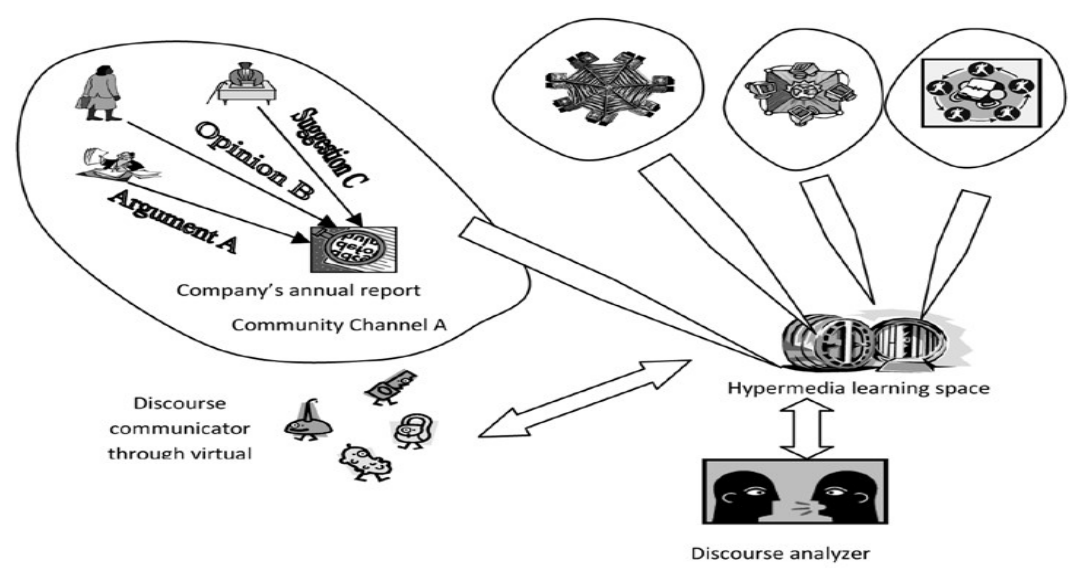

Fig. 6. Knowledge building in Hypermedia mode (adapted from (Syed Mustapha, 2004a)) 
Hypermedia learning space is a network structure, where each node in the network holds a fragment of learning object. Hypermedia is an enhanced feature of hyperlink where it supports access to all types of multimedia formatted objects. Hypermedia has been widely accepted in the field of educational technology (Dillon et al, 1998). Hypermedia can play the role to beef up the prior domain knowledge for students since the navigation behavior are strongly affected by understanding of the concept structure of the domain (Moos et al, 2007). It has been used for the implementation of problem-based learning when students desperately need to have fast access to information (Liu, 2004). There is an attempt to use hypermedia as the alternative to physical traditional lab session (Theyßen, 2005). Hypermedia offers random access at any point within the network structure that allows fast retrieval. The use of multifarious multimedia presentation makes the knowledge and information can be kept and delivered in the original form depending on the needs and suitability of the users. Hypermedia technology is adopted as the approach to support learning for the new generation students shy away from learning through linear process to non-linear since hypermedia technology allows "back-and-forth" movement (Lowe et al, 1998). ICC has been designed to support knowledge building based on hypermedia approach as shown in Figure 6.

Discourse analyzer plays important role in social knowledge building through monitoring and analyzing the dynamism of group interaction and topic of discourse. There are four important elements that to be analyzed which are the 1) intensity of participation measures the ratio between the numbers of participated activity of a member against the numbers of participated activity by all members 2) multiplicity in existence describes the versatility of a member in participating different subject matter 3) interactivity of the subtopic - uses standard deviation to measure the popularity of each subtopic and 4) social identity recognition - analyze the density of social interaction between all members (for detail refers to (Syed Mustapha, 2004d)).

Discourse analyzer performs the analysis on the community network to assist on building and managing the virtual community simulation. The virtual community consists of heterogeneous agents that supposedly embodied with different characteristics. The researcher sets the future work on embodied conversational and socially programmed agents that mimic the behavior of the specific member of the community. At present, the ICC was developed using Microsoft agents with different animated characters but without any special behavior as shown in Figure 7. The Query Text Box is an added functionality for the members in the community to converse and interact with the agents based on the existing community knowledge stored in the repository.

\section{Conclusion}

This paper has taken through the experiences in developing the learning system for the content knowledge and also social knowledge. Intelligent tutoring system general architecture has provided a framework that requires a long research endeavor to explore with respect to the knowledge building for content knowledge such as in rheol- 
ogy, chemistry, programming language etc. Even though the scope for content knowledge is well-defined and more structured, the development cost and man hours are horrendously huge. Despite, the capabilities to demonstrate amazingly intelligent behavior, the replication to other functionalities requires tireless effort. Social knowledge building system that poses greater challenge in knowledge modelling due to ill-defined knowledge scope and structure as well as capturing the learning behavior and cultural and social aspects of the community. It is emphasized in this paper that the new generation of learning theory has impressed on "learn-to-be" more than "learn about". The Intelligent Conversational Channel is built to support social knowledge building with strong emphasis on analyzing the underlying knowledge constructs and social networks in which many of the current social knowledge building system may not address strategically.

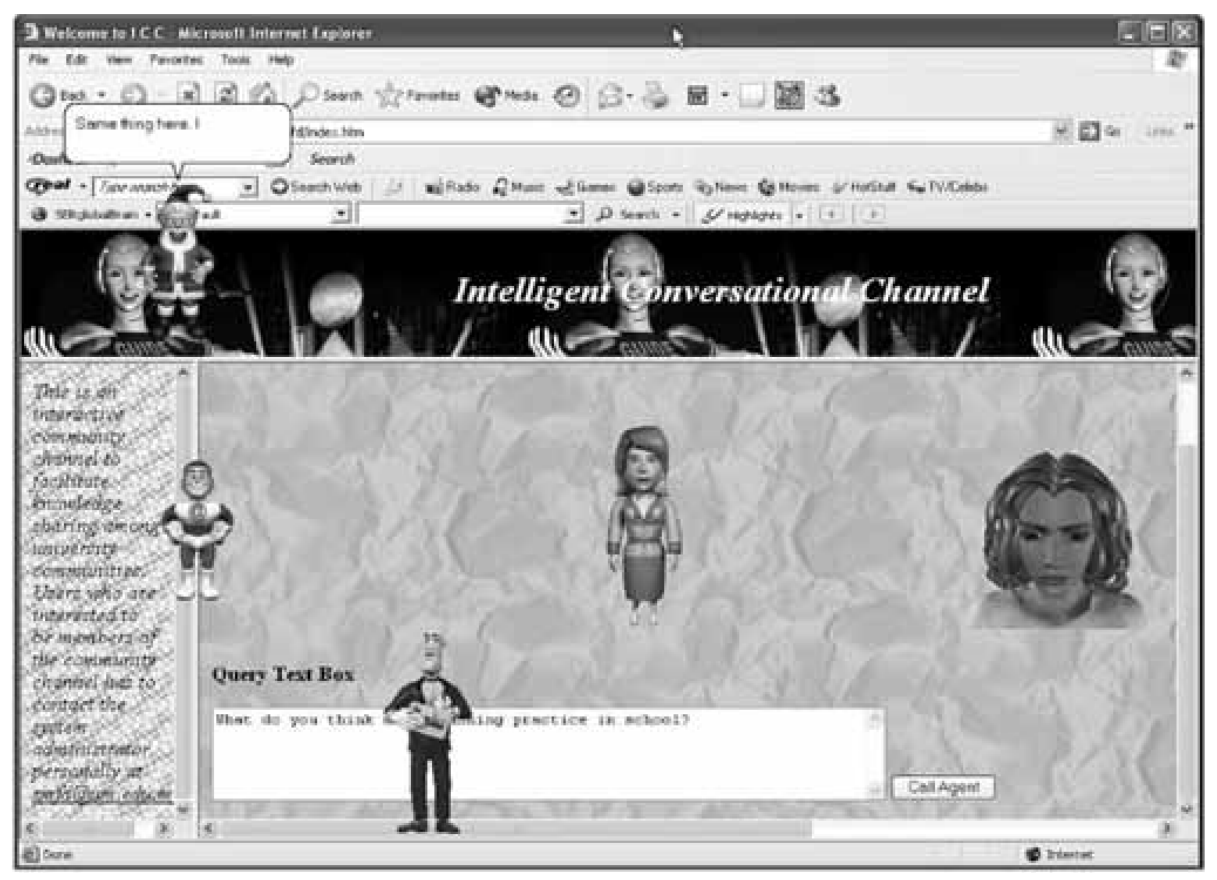

Fig. 7. Simulated Virtual Community based on Discourse Communicator (adapted from (Syed Mustapha, 2004a))

\section{$5 \quad$ References}

[1] Amin, S and Carrington, S. (2009). Expert System Rheometry. Materials Today, Volume 12, Issue 9, September 2009, pp.44 - 46. https://doi.org/10.1016/S1369-7021(09)70251-2

[2] Blyth, J.W. (1960). Teaching machines and Human Beings. The Educational Record (American Council in Education, 1785 Massachusetts Ave. N.W., Washington 6) April 1960, pp. $116-125$. 
[3] Crowder, N.A. (1959) Automatic tutoring by means of intrinsic programming. In $\mathrm{Au}$ tomatic Teaching: The State of the Art, Wiley, New York, pp.109-116.

[4] Denning, S. (2001). The Springboard: how story-telling ignites action in knowledgeera organizations. Butterworth-Heinemann.

[5] Dillon, A., and Gabbard, R. (1998). Hypermedia as an educational technology: A review of the quantitative research literature on learner comprehension, control and style. Review of Educational Research, 68, pp.322 - 349. https://doi.org/10.3102/00346543068003322

[6] Forbus, K. (2004). Qualitative Reasoning. CRC Handbook of Computer Science and Engineering, 2d Ed, Boca Raton, Fla: CRC Forthcoming.

[7] Galanter, E. (1959). Automatic teaching: the state of the art. New York 16, John Wiley \& Sons, Inc (Fourth Ave.).

[8] Hoadley, C and Kilner, P. (2005). Using Technology to Transform Communities of Practice into Knowledge Building Communities. SIGGROUP Bulletin, Vol 25, Number 1, pp.31 - 40. https://doi.org/10.1145/1067699.1067705

[9] Kendal, S.L.; Creen, M. (2007), An introduction to knowledge engineering, London: Springer.

[10] Liu, M. (2004). Examining the performance and attitudes of sixth graders during their use of a problem-based hypermedia learning environment. Computers in Human Behavior, 20 (2004), pp.357 - 379. https://doi.org/10.1016/S0747-5632(03)00052-9

[11] Lowe, D. and Hall, W. (1999). Hypermedia and the Web: An Engineering Approach, John Wiley.

[12] Lumsdaine, A.A and Robert, G. (1960) Editors. Teaching machine and programmed learning. Washington 6. National Education Association (1201 $16^{\text {th }}$ St. N.W), pp.724.

[13] Marshak, R.T. (1997). Workflow: Applying Automation to Group Processes. In: Coleman, D. (ed.): Groupware - Collaborative Strategies for Corporate LANs and Intranets. Prentice Hall, pp.143 - 181.

[14] Model Science Software, model Chemlab Software (2010), http://www.modelscience. com/index.html, last revised Jan 11, 2010.

[15] Moos, D.C. and Azevedo, R. (2008). Self-regulated learning with hypermedia: The role of prior domain knowledge. Contemporary Educational Psychology 33 (2008), pp.270 298. https://doi.org/10.1016/j.cedpsych.2007.03.001

[16] Mori, G., Paternò, F., Santoro, C. (2002). CTTE: Support for Developing and Analyzing Task models for Interactive System Design, IEEE Transactions on Software Engineering, vol.28, no.8, pp.797 - 813. https://doi.org/10.1109/TSE.2002.1027801

[17] Skinner, B.F. (1958). Teaching machines. Science. 128, pp.969 - 977. https://doi.org/10.1126/science.128.3330.969

[18] Skinner, B.F. (1961). Teaching machines. Scientific American (415 Madison Ave. New York 17), Nov 1961, pp.91 - 106. https://doi.org/10.1037/11324-011

[19] Stahl, G. (2000). A model of Collaborative Knowledge-Building. In B. Fishman \& S. O'Connor-Divelbiss (Eds.), Fourth International Conference of the Learning Sciences, Mahwah, NJ: Erlbaum, pp.70 - 77.

[20] Steffe, J.F. (1996) Rheological methods in Food Process Engineering, Freeman Press, MI, USA.

[21] Suppes, P. (1967) Some theoretical models for mathematics learning, Journal of Research and Development in Education 1, 522.

[22] Syed Mustapha, S.M.F.D. (1998). Visual Reasoning Using Qualitative Interpretation, National Conference in Cognitive Science, The Mines Resort, pp.213 - 220.

[23] Syed Mustapha, S.M.F.D. (2004a). Intelligent Conversational Channel for Learning Social Knowledge among Communities. 8th International Conference on Knowledge- 
based Intelligent Information \& Engineering System, KES 04, New Zealand, Vol I, pp. 343 - 349, 2004. https://doi.org/10.1007/978-3-540-30132-5 50

[24] Syed Mustapha, S.M.F.D. (2004b). An Algorithm for Avoiding Paradoxical Argument among the multi-Agent in the Discourse Communicator. 8th International Conference on Knowledge-based Intelligent Information \& Engineering System, KES 04, New Zealand, Vol I, pp.350 - 356, 2004.

[25] Syed Mustapha, S.M.F.D. (2004c) Towards Building Socially Intelligent KnowledgeBuilding System - in probe to missing component. Technical Report, Department of Information and Communication Engineering, School of Information Science and Technology, The University of Tokyo, EMEDIA 2004, pp.169 - 179.

[26] Syed Mustapha, S.M.F.D. (2004d) Agent mediated for intelligent conversational channel for social knowledge-building in educational environment. $5^{\text {th }}$ Int. Conf. on Information Technology Based Higher Education and Training: ITHET '04, $31^{\text {st }}$ May -2 June, 2004, pp.533 - 538 .

[27] Syed Mustapha, S.M.F.D., Moseley, L.G., Jones, T.E.R., Phillips, T.N. and Price, C.J. (1999). Viscometric flow interpretation using qualitative and quantitative techniques, International Journal of Engineering Applications in Artificial Intelligence, Vol 12, pp.255 - 272. https://doi.org/10.1016/S0952-1976(99)00002-0

[28] Syed Mustapha, S.M.F.D., Pang J.S. and Zain, S.M. (2002). Application Qualitative Process Theory to Qualitative Simulation and Analysis of Inorganic Chemical Reaction, $16^{\text {th }}$ International Workshop of Qualitative Reasoning, Barcelona, Spain, pp. $177-184$.

[29] Syed Mustapha, S.M.F.D., Phillips, T.N. (2002). Rheometer Advisory System - Embedding mixed-Initiative Approach Into Its Teaching and Learning Strategy, Journal of Applied System Studies, Vol.3, No.1.

[30] Syed Mustapha, S.M.F.D., Phillips, T.N. and Price, C.J. (1997) Towards characterization of viscoelastic behavior using model-based reasoning, $11^{\text {th }}$ International Workshop of Qualitative Reasoning, Italy, pp.297 - 304.

[31] Syed Mustapha, S.M.F.D., T.N. Phillips., C.J. Price., (1998) Case-Based Reasoning for Constructing Constitutive Equation for a Viscoelastic material in a Laminar Flow, Malaysian Journal of Computer Science, December 1998, Vol.11, No.12 pp.40 - 51.

[32] Theyßen, H. (2006): Students' Attitudes Towards the Hypermedia Learning Environment "Physics for Medical Students". http://www.eurodl.org/materials/ contrib/2006/Heike_Theyssen.htm (Download date: 28 February 2010).

[33] Trætteberg H. Workflow and task modelling. Proceedings of the Fourth International Conference on Computer-Aided Design of User Interfaces CADUI '99. Louvain-laNeuve, Belgium, 21 - 23 October 1999.

[34] Uhr, L (1969). Teaching machines programs that generate problems as a function of interaction with students. Proceedings of the $24^{\text {th }}$ National Conference, pp. $125-134$.

[35] Wenger, E. (1998). Communities of Practice: Learning, meaning and Identity, Cambridge University Press. https://doi.org/10.1017/CBO9780511803932

[36] Woods, P. \& Hartley, J.R. (1971) Some learning models for arithmetic tasks and their use in computer-based learning. British Journal of Educational Psychology, 41, pp.35 48. https://doi.org/10.1111/j.2044-8279.1971.tb00656.x

[37] Wu, H., Zubair, M. and Maly, K. (2006). Harvesting Social Knowledge from Folksonomies. HT'06, August 22 - 25, 2006, Denmark, pp.111 - 114 . 


\section{Author}

S.M.F.D Syed Mustapha is a professor in Computer Science Department, College of Computers and Information Technology, Taif University, Saudi Arabia. His main research interest is on building intelligent techniques through knowledge modelling for learning in which he had applied in various domains such as rheology, inorganic chemistry, social communication and community of practice. He received his $\mathrm{PhD}$ and MPhil from University of Wales, UK and Bachelor of Science (Computer Science) from University of Texas, USA. He has published more than 80 papers at the international journals and conferences in which $70 \%$ of the papers as the first author or single author. He was also recipients to various government research grant such as IRPA, FRGS and e-science in which he was the principal investigator. He had several years of experiences with industry when he was appointed as Principal Research Professional at British Telecom plc where he applied ontology in web service composition. He serves as board of reviewers in various scientific committee for international and local conferences and journals. He is a Fellow member of British Computer Society. He completed his postdoctoral programme under Hitachi Fellowship Foundation in University of Tokyo, Japan.

Article submitted 17 March 2017. Published as resubmitted by the author 23 June 2017. 